\title{
Digital Technologies in the Control System for Equipment Reconditioning in Oil and Gas Companies
}

\author{
E.V. Volkodavova ${ }^{1, *}$ and $O . V$. Tomazova $^{1}$ \\ "Corresponding author: vev.sseu@gmail.com \\ ${ }^{1}$ Samara State University of Economics, Samara, Russia
}

\begin{abstract}
In the era of global technological changes in oil and gas companies, business processes for extraction, processing and transportation of hydrocarbons are being improved, which requires modern high-tech equipment serving these technological processes. Ensuring trouble-free, uninterrupted operation of the equipment of oil and gas companies requires the introduction of digital technologies for its maintenance and repair. The relevance of this study is to develop digitalization of business processes for equipment reconditioning in oil and gas companies. The main business processes of extraction, transportation and processing of hydrocarbons are digitized quite fully. Supporting business processes of repair and maintenance of the equipment aimed at reconditioning and ensuring its smooth operation require further development based on their digitalization.
\end{abstract}

Keywords: business process, control system, digitalization, equipment reconditioning, oil and gas complex.

\section{Introduction}

Maintaining fixed assets in working condition and timely updating them has always been important for all industries. Recently, this issue is particularly acute in the oil and gas complex of the Russian Federation. Oil and gas companies use new technologies in the production process and, as a result, high-tech equipment.

The oil and gas complex of Russia is a combination of companies and organizations engaged in exploration, well construction, production, transportation, processing and sale of oil and gas. The oil and gas complex is a guarantee of Russia's economic security, since the share of its allocations is dominant in the country's budget.

Nevertheless, the country's oil and gas complex faces many problems, including those ones that ensure the operation of complex high-tech equipment:

- Difficulties with the supply of the equipment and components because of global sanctions;

- A large degree of depreciation of the means of labor of companies and organizations of the oil and gas complex.

Against the background of the problems identified, informatization and automation of the main and supporting business processes of Russian oil and gas companies contribute to reducing the costs of maintaining the equipment and increasing the competitiveness of oil and gas companies.

A well-planned reconditioning policy of the means of labor is one of the decisive factors in improving production efficiency, ensuring competitiveness and sustainable development of oil and gas companies in the current business environment.

\section{Problem Statement}

The study of modern scientific works highlights digitalization processes in the control system for equipment reconditioning in oil and gas companies, and we can conclude that such methodological solutions are narrow and fragmental in oil and gas companies. In addition, the impact of digital technologies on subjects and objects is limited to individual business processes. Digital technologies of supporting business processes are not accompanying in the implementation of core business processes in known digital technologies.

If we consider the best practices of digitalization of business processes in relation to oil and gas companies, then first, we should note such companies as:

- Shell, "Smart Field" - "is a control system for production, which allows, on the one hand, increasing the production of oil or gas, and on the other, optimizing the cost of energy consumed" [1].

- Chevron, "Intellectual Field" (i-Field) - "is a management concept that uses data from various processes, allows moving from local optimization of each process to global optimization of the field" [2].

- Halliburton, "Real Time Operations" is "a software that includes a set of applications that allow describing the behavior of a field on a computer" [3].

- Schlumberger, "Smart Wells" - "is designed for permanent monitoring and control of the well throughout its life span, from the cementing stage to its liquidation" [4]. 
- ADCO, "Integrated Asset Operation Model (IAOM)) -" is the state of a digital production asset, which implements control based on a set of digital integrated models (digital asset double), which allow predicting and optimizing the entire process, work and resources based on real-time data".

As can be seen from the characteristics of the above digital technologies, they relate to the main business processes. An equally important task is the creation of digital technologies for supporting business processes. It concerns the repair and maintenance of the equipment that provides the main business processes for exploration, production, transportation and processing of hydrocarbons. Therefore, the authors defined the following tasks in the study:

- Evaluate the existing control system for equipment reconditioning in Russian oil and gas companies;

- Determine the level of digitalization of the studied business processes;

- Develop a control system for digitization of business processes for equipment reconditioning in the oil and gas complex.

\section{Research Questions}

\subsection{Characteristics of the applied control system for equipment reconditioning in Russian oil and gas companies}

Under current economic conditions, in most cases, oil and gas companies use a system of preventive maintenance for equipment reconditioning.

Lengthening the service life of the equipment requires preventive measures and timely and high-quality repairs. The uninterrupted operation of the equipment is ensured by the system of scheduled maintenance, including a set of planned measures to ensure the maintenance, supervision and repair of fixed assets. This system includes measures for the dayto-day maintenance of the equipment and the carrying out of current, medium and major repairs.

\subsection{Assessment of the level of digitalization of the control system for equipment reconditioning in Russian oil and gas companies}

A few processes are provided with digital technologies in the control system for equipment. Individual oil and gas companies use modules TOPO SAP ERP. "Due to a large scale of production, companies have a complex database structure, part of which is the data of TOPO SAP ERP maintenance module. This functional module maintains the equipment in a stable condition and helps to produce efficient production planning. The TORO complex has a direct connection with technical diagnostics of the equipment" [5].

The existing systems for fixed assets reconditioning in Russian oil and gas companies require further development by introducing new digital technologies. The development of digitalization of the control system for equipment reconditioning will have a significant impact on the adoption of effective management and technological decisions in the activities of oil and gas companies [6].

The study carried out by the authors in oil and gas companies of the Samara region [7] suggests that many business processes of the preventive maintenance system require development based on digitalization. This is especially true for "maintenance", most often performed by the services of the chief mechanic in oil and gas companies. For each business process, key sub-processes were identified, for the development of which digital technologies are effectively applied (see Fig. 1). Maintenance for oil and gas companies is performed differentially, depending on the environment in which they operate. Since the bulk of the equipment, for example, oil wells, pipelines, etc., work in different climatic and geological conditions, and a complex of seasonal maintenance is additionally carried out. Digitization of business processes for maintenance and repair will significantly reduce management decision-making in the field of equipment reconditioning located, sometimes thousands of kilometers away from the company's head office.

\subsection{Development of a control system for digitization of business processes for equipment reconditioning in oil and gas companies}

One of the ways to develop a control system for repair and maintenance of the equipment in oil and gas companies is the use of digital technologies.

The purpose of creating a modern control system for equipment reconditioning in the studied companies is to increase production efficiency. Figure 1 shows the system developed by the authors for controlling digitalization of the key, most frequently performed business processes: maintenance and repair of the equipment in oil and gas companies.

The new control system for equipment reconditioning will also allow companies to:

- Systematize information about available items of labor, tools, spare parts and accessories and store this information in electronic form;

- Efficiently plan preventive and repair work, monitor the progress of execution of these works;

- Reduce the number of accidents and downtime due to equipment failures;

- Reduce operating costs and losses by eliminating inefficient types of unscheduled and preventive maintenance. 


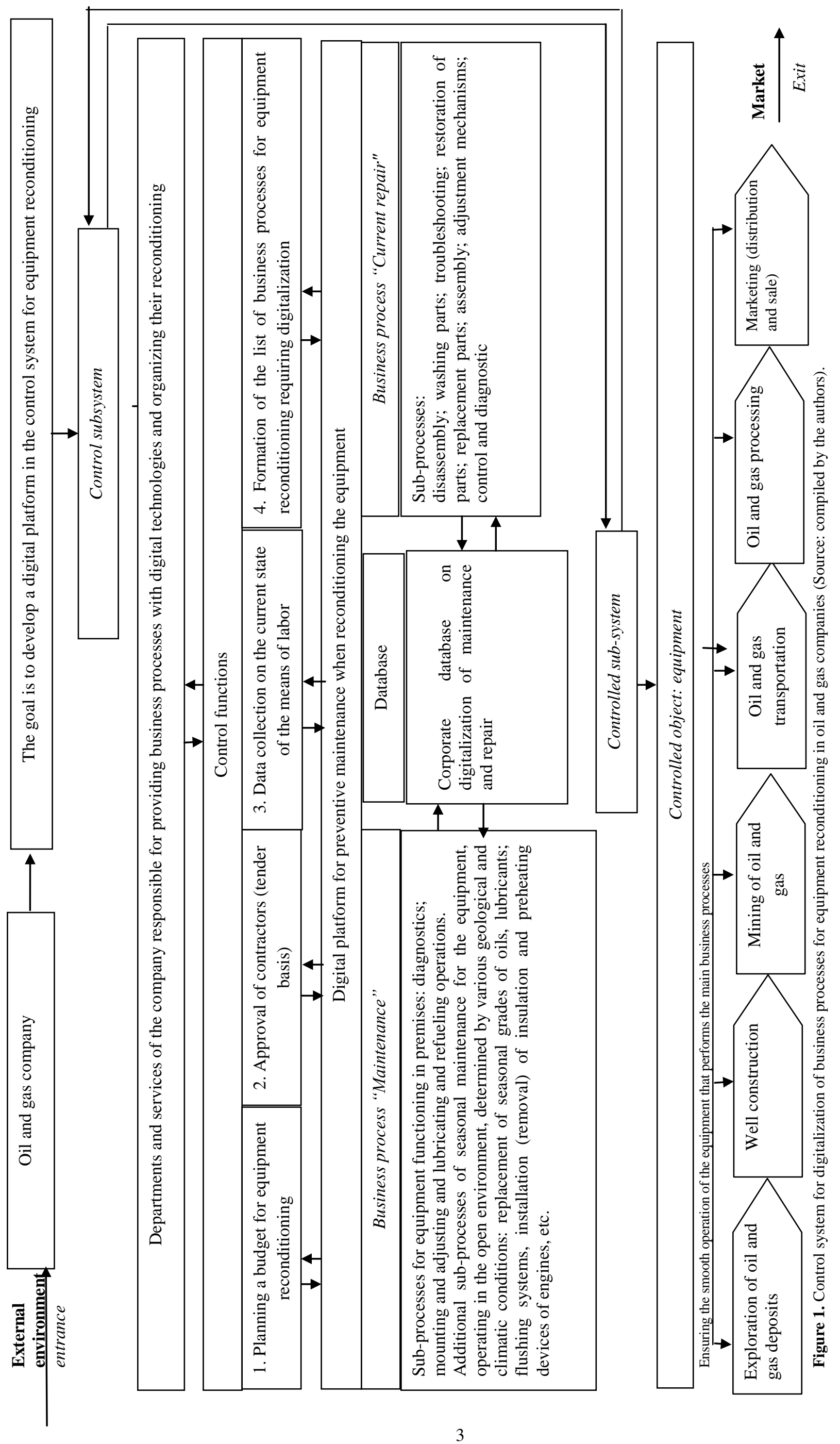




\section{Purpose of the Study}

The purpose of the study is to develop a control system for equipment reconditioning in oil and gas companies through digitalization of supporting business processes. The authors have conducted their study based on the analysis of works of other scientists in this sphere [8-10].

\section{Research Methods}

The following methods were used during the research:

- A system analysis method that allowed researching business processes and equipment reconditioning algorithms, identifying their interconnection, sequence of operations and determining the direction of digitalization of business processes for equipment reconditioning;

- A method of complex analysis, which made it possible to cover a wide range of aspects of the application of digital technologies in planning and organizing equipment reconditioning in foreign and Russian oil and gas companies;

- A field research method, which allowed forming a database for actual equipment reconditioning in relevant services of oil and gas companies and assess their performance.

\section{Findings}

In the course of the study, the authors obtained the following results:

The authors analyzed the existing control system for equipment reconditioning in oil and gas companies; assessed the level of digitalization of supporting business processes of repair and maintenance of the equipment, the effective performance of which ensures uninterrupted operation of fixed assets of oil and gas companies operating in various climatic conditions.

Key supporting business processes were identified, digitalization of which will improve the quality of the equipment operation and the efficiency of the main production processes for exploration, production, transportation and processing of hydrocarbons.

Taking into account the identified business processes to be digitized, oil and gas companies developed a control system for equipment reconditioning on a technological platform. The developed system for equipment reconditioning, covering the key sub-processes of business processes of maintenance and repair, actually expands the use of the preventive maintenance system, ensuring their further information and technological development.

\section{Conclusion}

The oil and gas complex is one of the main elements of the Russian economy, and its condition has a significant impact on many sectors of the Russian economy. In turn, the efficiency and dependability of fixed assets in the system of supporting business processes of the system of preventive maintenance ensures the efficiency of operations, competitiveness and stability of the oil and gas industry in global market segments. Further development of equipment reconditioning in oil and gas companies is possible, primarily based on its digitalization.

The proposed measures for the development of the preventive maintenance system based on digital technologies will ensure that the management of oil and gas companies make informed optimal management decisions in the area of available equipment reconditioning.

The implementation of the processes described above as part of the implementation of the preventive maintenance system in oil and gas companies will contribute to the improvement of equipment reconditioning and does not require substantial capital investments.

\section{References}

1) N.A. Yeremin, Modern development of oil and gas. Smart well. Intellectual fishing. Virtual Company: Manual for universities. Moscow: LLC Nedra-Business Center (2008). [in Rus.].

2) M. Cherkasov, Schneider Electric. The concept of "Smart Field". Portal "Energy", efficient energy supply. Section: Energy Saving Technologies. URL: http://portal-energo.ru/articles/details/id/950. Accessed: 17/01/2019 (2016). [in Rus.].

3) A. Gomonov, Management in real time: What, where, when. Intelligent Enterprise, 18(104). URL: https://www.iemag.ru/opinions/detail.php?ID=17825. Accessed: 17/01/2019 (2004). [in Rus.].

4) A.M. Kornaukhov, Prospects for the digitalization of research activities in exploration. Petroleum Geology. Theory and Practice, 12(4), 1-10. URL: http://ngtp.ru/rub/2017/44_2017.html. DOI: 10.17353/2070-5379/44_2017 (2017). [in Rus.]. 
5) E.Yu. Andiyeva, O.N. Kaneva, D.S. Markelov, A.V. Chaadaev, Algorithm for preliminary analysis of data information content of the SAP ERP maintenance module. Applied Mathematics and Fundamental Informatics, 1(5), 66-75 (2018). [in Rus.].

6) E.V. Volkodavova, O.V. Tomazova, Using a digital platform to model interaction between oilfield service market actors. Helix, 8(6), 4707-4716. DOI 10.29042/2018-4707-4716 (2016).

7) E.V. Volkodavova, O.V. Tomazova, Methodological approach to improving the equipment reconditioning control tool in oil and gas companies. Journal of Internet Banking and Commerce, 21(3), 1-17 (2016).

8) C.F. Berg, O. Lopez, H. Berland, Industrial applications of digital rock technology. Journal of Petroleum Science and Engineering, 157, 131-147. DOI: 10.1016/j.petrol.2017.06.074 (2017).

9) G. Carvajal, M. Maucec, S. Cullick, Introduction to digital oil and gas field systems. In G. Carvajal, M. Maucec, \& S. Cullick (Eds.) Intelligent digital oil and gas fields. Concepts, collaboration, and right-time decisions, (pp. 1-41). Elsevier: Gulf Professional Publishing. https://www.sciencedirect.com/science/article/pii/B9780128046425000013?via\%3Dihub. DOI: 10.1016/B978-0-12804642-5.00001-3 (2018).

10) J. Wu, Based on GIS Oil and Gas Field Company seismic data loading quality control system architecture design. Procedia Environmental Sciences, 10(PART B), 974-979. DOI: 10.1016/j.proenv.2011.09.156 (2011). 